\section{Commentary: Is the health of the forest measured by the health of some of the trees?}

\author{
David Bichell, MD
}

The Stanford experience with pulmonary artery unifocalization has set the standard for the treatment of pulmonary atresia with ventricular septal defect (PAVSD) with multiple aortopulmonary collaterals (MAPCAs). Mainwaring and colleagues ${ }^{1}$ describe the midterm fate of 129 unifocalized MAPCAS in 37 patients with retroesophageal MAPCAs (REMs), a subset of PAVSD/MAPCA patients constituting about $10 \%$ of that institution's volume.

Previous work by the same authors, on the same study population, show that REMs are different from anterior MAPCAs in a variety of ways, including a higher likelihood of absent dual supply, higher likelihood of stenosis of the native connection, and higher success of unifocalization. ${ }^{2}$

It is the authors' hypothesis that the fate of individual MAPCAs in aggregate would be a strong determinant of the clinical outcome. The dataset, viewed in this analysis as per-MAPCA success (129 MAPCAs unifocalized) rather than per-patient success (37 patients), reveal some useful anatomic predictors, but leave opportunity to learn more. At median 11-month follow-up catheterization, REMs outperformed the aggregate consideration of all others, with $85 \%$ widely patent and $2 \%$ occluded, versus $75 \%$ patent and 5\% occluded among non-REM MAPCAs. Notably, all 5 patients with absent central PAs required surgical revision, and patients with REMs had a higher prevalence of

\footnotetext{
From the Department of Cardiac Surgery, Vanderbilt University Medical Center, Monroe Carell, Jr. Children's Hospital, Nashville, Tenn.

Disclosures: The author reported no conflicts of interest.

The Journal policy requires editors and reviewers to disclose conflicts of interest and to decline handling or reviewing manuscripts for which they may have a conflict of interest. The editors and reviewers of this article have no conflicts of interest.

Received for publication Oct 16, 2021; revisions received Oct 16, 2021; accepted for publication Oct 18, 2021; available ahead of print Oct 21, 2021.

Address for reprints: David Bichell, MD, Department of Cardiac Surgery, Vanderbilt University Medical Center, Monroe Carell, Jr. Children's Hospital, 5247 Doctors' Office Tower, 2200 Children's Way, Nashville, TN 37232-9292 (E-mail: david. bichell@vumc.org).

J Thorac Cardiovasc Surg 2022;163:2183-4

$0022-5223 / \$ 36.00$

Copyright (c) 2021 by The American Association for Thoracic Surgery

https://doi.org/10.1016/j.jtcvs.2021.10.025
}

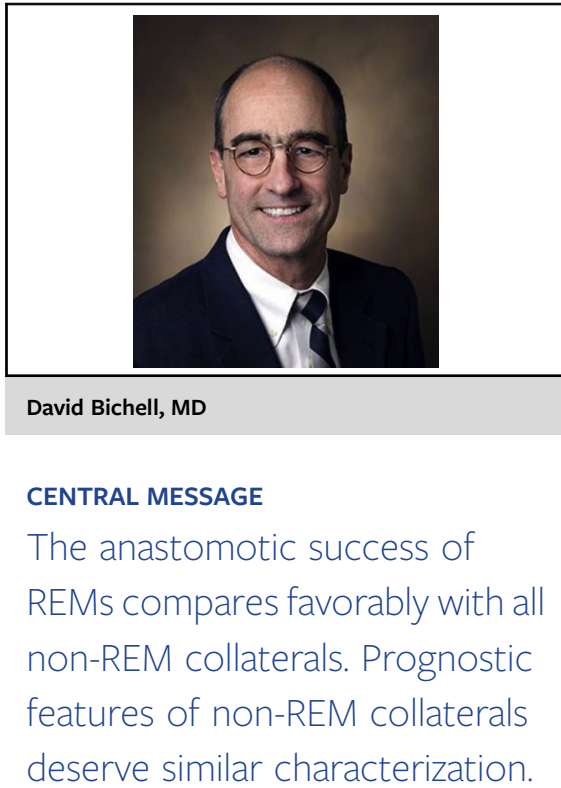

absent central PAs. The analysis did not include consideration of distance from the hilum of MAPCA aortic origin, caliber of MAPCAs unifocalized, or other distinguishing features of the widely varied non-REM MAPCAs.

MAPCAs with more remote origins may pose different risks than those less displaced from the hilum. Absent central PAs are different expectations than confluent PAs or unilateral PAs. Patch augmented MAPCAs may fare differently than those of sufficient caliber to implant directly. A comparison of REM to all other MAPCAs is informative, but it could be more informative to go beyond a dichotomous comparison of REMs to all others.

It is also difficult to untangle the effect of 22q11 chromosome deletion, highly prevalent among PAVSD/MAPCA patients, and associated bronchomalacia on pulmonary vascular health. ${ }^{3-5}$ Although the fate of individual MAPCAs may be a strong determinant of overall anastomotic outcome, extracardiac characteristics also weigh heavily on a patient's ultimate overall outcome. Per-MAPCA success tells only part of the outcome story for these patients.

The heterogeneous population of patients with PAVSD/ MAPCAs is challenging to risk-stratify. Mainwaring and colleagues ${ }^{1}$ have added important insight into the fate of retroesophageal MAPCAs compared with all other MAPCAs. Impressive per-MAPCA results encourage an optimistic pulmonary vascular outlook for these patients overall. Further study of data from this institution's large 
experience may build an even more comprehensive encyclopedia of MAPCA morphologies and their implications.

\section{References}

1. Mainwaring RD, Capecci L, Collins T, Hanley FL. Midterm fate of unifocalized major aortopulmonary collateral arteries in patients with retroesophageal major aortopulmonary collateral arteries. J Thorac Cardiovasc Surg. 2022;163:2175-81.

2. Mainwaring RD, Adamson G, Hanley FL. To unifocalize or not to unifocalize? A comparison of retro-esophageal versus anterior collaterals. Ann Thorac Surg.
February 22, 2021; https://doi.org/10.1016/j.athoracsur.2021.02.017 [Epub ahead of print].

3. Perri G, Albanese SB, Carotti A. Airway complications after single-stage unifocalization for pulmonary atresia, ventricular septal defect, and major aortopulmonary collateral arteries. J Card Surg. 2015;30:453-8.

4. Sacca R, Zur KB, Crowley TB, Zackai EH, Valverde KD, McDonaldMcGinn DM. Association of airway abnormalities with 22q11.2 deletion syndrome. Int J Pediatr Otorhinolaryngol. 2017;96:11-4.

5. Mahle WT, Crisalli J, Coleman K, Campbell RM, Tam VKH, Vincent RN, et al. Deletion of chromosome 22q11.2 and outcome in patients with pulmonary atresia and ventricular septal defect. Ann Thorac Surg. 2003;76:567-71. 